\title{
KOLLEKTIEWE BEDINGING BINNE DIE SUID-AFRIKAANSE \\ VERVAARDIGINGSBEDRYFTAK
}

\author{
H.O.L. KAMFFER * \\ B.C. LESSING \\ M.M. FOUCHÉ \\ P.E. CONSULTING GROUP \\ DEPARTEMENT BEDRYFSIELKUNDE RANDSE \\ AFRIKAANSE UNIVERSITEIT
}

\begin{abstract}
A comparative literary study of the collective bargaining systems of four countries (U.S.A., Britain, West Germany and South Africa) is presented in order to facilitate the identification of conflict issues in the South African collective system. 165 Employers and 75 trade unions in the South African manufacturing industry were used as $u$ randomly selected sample. A Likert questionnaire was designed to measure the attitudes of the sample employers and unions regarding conflict issues. The results indicate strong differences of opinion between the participating groups about the efficiency of the present industrial relations and collective bargaining systems in South Africa. An explanation for obtained results is given and recommendations for further research and development work are made.
\end{abstract}

Nywerheidsgroei in Suid-Afrika gedurende die sestiger en sewentiger jare het meegebring dat plaaslike nywerheidsorganisasies geweldig uitgebrei het. Hierdie nywerheidsgroei met die meegaande uitbreiding van produksiefaktore is 'n proses wat dwarsdeur die wêreld plaasvind maar wat in Suid-Afrika baie ingewikkeld is as gevolg van die bykomende rasseverskille, kommunikasieprobleme (as gevolg van verskillende etniese groepe en tale) en die verskillende sosiale en politieke ontwikkelingsvlakke wat die verskillende bevolkingsgroepe bereik het. Die ingewikkeldheid van hierdie situasie verg dat Suid-Afrikaanse nywerheidsverhoudinge soveel meer doeltreffend moet wees as wat 'n homogene situasie sou vereis. Dit is vanselfsprekend dat hierdie ingewikkelde situasie, wat met 'n wedersydse gebrek aan vertroue tussen die verskillende bevolkingsgroepe gepaard gaan, die Suid-Afrikaanse kollektiewe bedingingsprosesse versteur en bemoeilik.

\footnotetext{
* Versoeke vir afdrukke moet aan die eerste skrywer gerig word.
} 
Weens die omvangrykheid en interdissiplinêre aard van hierdie studieterrein bestaan daar wyduiteenlopende definisies vir die begrip nywerheidsverhoudinge. Wanneer na 'n doelmatige definisie gesoek word, moet vermy word om 'n definisie daar te stel wat net die formele verhouding betrek soos wat dit in die bedryf tussen formele werkgewer/werknemerorganisasies bestaan.

So definieer Barbash (1967) byvoorbeeld nuwerheidsverhoudinge as: "The area of study and practive concerned with the administration of the employment function in modern public and private enterprise, this function involves workers' unions, managers and the State". Clegg (1979) beskryf nywerheidsverhoudinge weer as: "The study of the rules governing employment, together with the ways in which the rules are made and changed, interpreted and administered". Sulke definisies impliseer verkeerdelik dat nywerheidsverhoudinge slegs met georganiseerde arbeid te doen het. Bedrywe waar daar nie formele werkgewer/werknemerorganisasies bestaan nie, word egter ook by nywerheidsverhoudinge betrek. In die lig hiervan verskaf Weber (1961) 'n aanvaarbare definisie van nywerheidsverhoudinge "... it covers all forms of economic activity or production and all forms of labour relationships, regardless of the presence, absence or variety of formal organisations".

Kollektiewe bedinging aan die ander kant is ' $\mathrm{n}$ proses wat gebore is uit ' $\mathrm{n}$ spesifieke behoefte by werknemers om hulle belange te beskerm en het dus as proses saam met die vakbondwese ontwikkel. Holley en Jennings (1980) definieer kollektiewe bedinging binne 'n breë raamwerk as: "... a process whereby union and management officials attempt to resolve conflicting interests on various working conditions in a manner that will sustain and enrich their continuing relationship". Kollektiewe bedinging skep dus die geleentheid vir ordelike beslegting van geskille. Dit waarborg egter nie volkome bevrediging van eise en behoeftes nie, maar deur die kommunikasie wat tydens onderhandeling geskied, raak bestuur en werknemers meer bewus van mekaar se behoeftes en die regverdiging daarvan. Daarin is 'n geleentheid om eie behoeftes in 'n toenemende mate ondergeskik te stel aan 'n gesamentlike doelwit wat tydens kollektiewe bedinging geïdentifiseer kan word.

Daar bestaan 'n gebrek aan konsensus en sterk meningsverskille onder betrokkenes omtrent die doeltreffendheid van bestaande Suid-Afrikaanse nywerheidsverhoudinge en kollektiewe bedingingstelsels. Aan vakbondkant kan daar vir hierdie doeleindes onderskei word tussen gevestigde en opkomende vakbonde. Die gevestigde vakbonde (meestal Blank) is relatief tevrede met die huidige stelsel omdat hulle daarmee vertroud is en 'n sterk bedingingsposisie daarin beklee. Aan die ander kant van die skaal word ontevredenheid en verwerping 
gemonster deur die opkomende en jong vakbonde (meestal Swart), aangesien die nuwe toetreders tot die stelsel volgens hulle siening geen sterk bedingingsmag besit nie. Ook die werkgewer word hiermee gekonfronteer en moet sekere keuses uitoefen omtrent erkenning van bedingingspartye en die meegaande proses van bedinging.

In die navorsing wat hier gerapporteer word gaan dit oor houdings van die betrokke partye tot nywerheidsverhoudinge en meer spesifiek om die kollektiewe bedingingstruktuur krities te analiseer om die uitwerking van hierdie houdings op die interaksieproses vas te stel. Die doelstellings van die studie kan meer spesifiek as volg gestel word:

- $\quad$ om deur middel van 'n evaluerende literatuurstudie die kollektiewe bedingingstelsels van vier lande, naamlik Verenigde State van Amerika, Verenigde Koningkryk, WesDuitsland en Suid-Afrika te vergelyk met die oog op die identifisering van konflikaangeleenthede binne die Suid-Afrikaanse kollektiewe bedingingstelsel

- $\quad$ om die houdings van 'n aantal werkgewers en vakbonde binne die Suid-Afrikaanse vervaardigingsbedryfstak ten opsigte van hierdie konflikaangeleenthede met behulp van 'n houdingsvraelys te toets

- $\quad$ om, na aanleiding van die resultate van die empiriese studie oor die partye se houdings ten opsigte van die genoemde konflikpunte, sekere aanbevelings vir 'n progressiewe kollektiewe bedingingstelsel in Suid-Afrika te maak.

\section{METODE}

\section{Die Steekproef}

Die Suid-Afrikaanse vervaardigingsbedryfstak is as toepassingsgebied vir hierdie studie gekies hoofsaaklik omdat beide werkgewers en werknemers nywerheidsverhoudinge-bewus is, asook omdat werknemers ten opsigte van vakbonde relatief goed georganiseerd is. Die steekproef bestaan uit 165 werkgewers en 75 vakbonde in vervaardigingsbedryfstak.

Die 165 werkgewers is willekeurig uit 'n lys van vervaardigingswerkgewers gekies terwyl die 75 vakbonde al die vakbonde binne hierdie bedryfstak verteenwoordig. Meer spesifiek is die volgende vakbondgroepe by hierdie studie betrek:

- Vakbondraad van Suid-Afrika (Tucsa)

- $\quad$ Federasie van Suid-Afrikaanse vakbonde (Fosatu) 
- $\quad$ Raad van vakbonde van Suid-Afrika (Cusa)

- $\quad$ Nie-geaffillieerde geregistreerde vakbonde

- Nie-geaffillieerde ongeregistreerde vakbonde

\section{Meetinstrument}

Konflikaangeleenthede binne die Suid-Afrikaanse kollektiewe bedingingstelsel is aan die hand van die volgende struktuur geïdentifiseer:

- wetlike raamwerk

- $\quad$ partye betrokke

- $\quad$ masjinerie en vlakke van kollektiewe bedinging

- $\quad$ bestek van bedinging

- erkenningsooreenkomste

- dispuutprosedures

- $\quad$ inmenging deur buitestaanders

- $\quad$ verhoudinge tussen partye

'n Likert-tipe houdingskaal bestaande uit 42 items is hieruit ontwikkel as basis vir die vasstelling van deelnemers se houdings omtrent die geïdentifiseerde konflikaangeleenthede. (Kyk Kamffer, 1983).

\section{Insameling van data}

Die houdingsvraelys is aan die geïdentifiseerde streekproefgroep gepos tesame met 'n dekbrief deur die skrywer onderteken asook 'n ondersteunende dekbrief wat deur die Departement Bedryfsielkunde (RAU) voorsien is. In die geval van werkgewers is vraelyste aan die Personeel-Nywerheidsverhoudingebestuurders en in vakbonde se geval aan die onderskeie Sekretarisse gestuur. Tabel 1 toon die finale terugsendingspersentasies vir die onderskeie groepe aan.

\section{Statistiese verwerking van data}

Die vraelysdata is met behulp van 'n SPSS rekenaarprogram verwerk. Alhoewel chikwadraatverwerkings gedoen is, is hoofsaaklik van frekwensietabelle gebruik gemaak om die onderskeie partye se houdings omtrent die vraelysitems te ondersoek. 
TABEL 1

\section{TERUGSENDINGSPERSENTASIES VIR DEELNEMENDE GROEPE}

\begin{tabular}{l|c|c|c}
\hline \multicolumn{1}{c|}{$\begin{array}{c}\text { Deelnemende } \\
\text { groep }\end{array}$} & $\begin{array}{c}\text { Aantal vrae- } \\
\text { lyste uitgestuur }\end{array}$ & $\begin{array}{c}\text { Aantal vrae- } \\
\text { lyste terugontvang }\end{array}$ & $\begin{array}{c}\text { Respons } \\
\%\end{array}$ \\
\hline Vakbondgroep & 32 & 14 & 44 \\
Tucsa & 10 & 5 & 50 \\
Fosatu & 7 & 4 & 57 \\
Cusa & 21 & 11 & 52 \\
$\begin{array}{l}\text { Nie-geaff. geregi } \\
\text { streerd }\end{array}$ & 5 & 2 & 40 \\
Nie-geaff. onge- & 75 & 36 & 48 \\
registreerd & 165 & 100 & 60 \\
\hline TOTAAL (Vakbonde) & &
\end{tabular}

RESULTATE

Hierdie studie het die sterk meningsverskille wat daar omtrent die doeltreffendheid van die bestaande nywerheidsverhoudinge- en kollektiewe bedingingstelsel in Suid-Afrika bestaan, geïdentifiseer. Die resultate van hierdie studie en die gevolgtrekkings wat daaruit vloei, word vervolgens kortliks bespreek:

\section{Wetlike raamwerk}

$\mathrm{Al}$ die betrokke partye stem saam dat die rol van arbeidswetgewing slegs die regulering van die bedingingsverhouding inhou en nie direkte inmenging in die verhouding wettig nie. Beide werkgewers en vakbonde wil dus toesien dat hierdie grondbeginsel van kollektiewe bedinging nagekom word, dit wil sê hierdie partye besef dat arbeidsvrede hoofsaaklik hulle eie verantwoordelikheid is. Daar bestaan egter steeds verdeeldheid omtrent die mate waarin die bestaande arbeidswetgewing al die betrokke partye akkommodeer nieteenstaande die onlangse progressiewe wysiging in wetgewing. Hierdie verdeeldheid kan aan konserwatisme en liberalisme, wat op die pole van die nywerheidsverhoudinge voorkom, toegeskryf word. Voortdurende waaksaamheid om met veranderde omstandighede tred te hou, moet dus deur die Staat gehandhaaf word. Dit is verblydend dat die Nasionale Mannekragkommissie in hierdie verband voortdurend progressiewe hervormings ondersoek en aanbevelings aan die Minister van Mannekrag maak. 


\section{Partye betrokke}

Terwyl al die partye oorwegend saamstem dat vakbonde en werkgewers medeverantwoordelik vir arbeidsvrede is, bestaan daar verdeeldheid omtrent die status van veral vakbonde. Vakbonde voel in 'n groot mate dat hulle nie die volle erkenning van werkgewers ontvang nie as gevolg van die tradisionele konflik tussen werkgewers en vakbonde. $\mathrm{Al}$ die partye keur ook oorwegend die tendens van splintervakbonde af omdat dit die kwaliteit van werknemers-verteenwoordiging verswak en geen werklike voordele vir lede inhou nie.

\section{Masjinerie en vlakke van kollektiewe bedinging}

Die enigste definitiewe tendens wat hier na vore gekom het, is dat deelnemende partye op grond van veral hulle tradisionele verbintenis in twee duidelik skeibare groepe verdeel kan word. Aan die een kant is daar partye wat gesentraliseerde bedinging voorstaan terwyl ander meer gedesentraliseerde bedinging verkies. Tog blyk dit dat daar 'n sensitiwiteit vir mekaar se standpunte bestaan asook die besef dat daar wel ruimte vir albei stelsels in die vervaardigingsbedryf is. Die oorwegende gevoel is dat daar gesamentlik oor moontlike wysigings vir die gesentraliseerde stelsel beraadslaag moet word om sodoende alle betrokke partye se behoeftes te inkorporeer en nie net die van partye wat tradisioneel met die instelling geassosieer het nie.

Die meerderheid van partye besef ook dat werksrade tans nie as volwaardige bedingingsliggame funksioneer nie maar eerder as konsultasieliggame. Daar sal dus na hierdie huishoudelike instelling vir kollektiewe bedinging gekyk moet word om die onsekerheid by arbeidspartye omtrent die funksionering daarvan uit te skakel.

\section{Bestek van bedinging}

Alhoewel die meerderheid van die deelnemende partye saamstem dat alle items waaroor die partye kan ooreenstem om te onderhandel op kollektiewe bedinging van toepassing is en daar dus geen teoretiese limiete bestaan nie, is bedingingsitems afhanklik van die bepaalde vlak waar bedinging plaasvind. Die partye wat gesentraliseerde bedinging tradisioneel ondersteun, verkies dat alle riglyne vir die bedryf deur die nywerheidsrade voorgeskryf moet word, terwyl slegs huishoudelike aangeleenthede op fabrieksvlak hanteer moet word. Ondersteuners van gedesentraliseerde bedinging wil egter hê dat meer outonome bedinging op fabrieksvlak moet plaasvind. 


\section{Erkenningsooreenkomste}

Die reaksies van die deelnemende partye het bevestig dat polarisasie tussen gesentraliseerde en gedesentraliseerde bedinging tans bestaan. Die partye tot gesentraliseerde bedinging skram weg van die implikasie van erkenningsooreenkomste terwyl die gedesentraliseerde ondersteuners besef dat die voordele van hierdie vorm van bedinging tans groter as die nadele daaraan verbonde is. Die gewildheid van erkenningsooreenkomste maak dit egter noodsaaklik om op die implikasie daarvan te let, naamlik 'n toename in gedesentraliseerde bedinging.

\section{Dispuutprosedures}

Die oorwegende mening van al die partye is dat daar tans heelwat onsekerheid omtrent die doel en funksionering van die Nywerheidshof bestaan. Die effektiwiteit van hierdie huidige instelling word bevraagteken. Omdat die Nywerheidshof 'n sensitiewe rol vervul om die versteurde bedingingsverhouding te herstel, moet hierdie instelling aanvaarbaar en verstaanbaar vir alle partye wees voordat dit met welslae kan funksioneer.

\section{Inmenging deur buitestaanders}

Die meerderheid van die deelnemers is van mening dat inmenging deur veral veiligheidsowerhede in nywerheidsverhoudinge die progressiewe hervormings soos deur nuwe arbeidswetgewing daargestel, benadeel. Die probleem hier ter sprake is egter een met wyer implikasies as net nywerheidsverhoudinge. Dit gaan oor die sosiale-, ekonomiese- en politieke implikasies van die interaksie tussen werkgewers, vakbonde en die Staat. Terwyl die konserwatiewe vakbonde en werkgewers die rol van vakbonde sien as een wat beperk is slegs tot werksaangeleenthede, is die vakbonde wat gedesentraliseerde bedinging voorstaan van mening dat vakbonde se verantwoordelikhede wyer as slegs werksaangeleenthede strek. Juis hierdie houding, naamlik om die werknemer in sy totale omgewing te ondersteun, lei tot ingryping deur veiligheidsowerhede wat ondermyning van staatsveiligheid deur arbeidspartye wil voorkom. Hierdie inmenging, gewens of nie, beïnvloed egter die bedingingsverhouding daar vakbondleiers uit hul poste geneem word wat die vakbonde sonder enige leiers laat. Werkgewers is angstig om met verantwoordelike leiers te onderhandel en die inmenging van staatsweë plaas die uiters sensitiewe verhouding nog meer in gevaar. 


\section{Verhoudinge tussen partye}

Alle partye is dit eens dat die aanvangsfase van onderhandelinge tussen vakbonde en werkgewers konstruktief hanteer moet word om die bedingingsverhouding positief te bou. Partye moet 'n ewe sterk wil openbaar om konstruktief en met integriteit te beding om oor die langtermyn vir beide groepe voordele te waarborg en bevredigende ooreenkomste daar te stel. Werkgewers en die ouer gevestigde vakbonde het optimisties omtrent die toekoms van nywerheidsverhoudinge in Suid-Afrika gereageer terwyl daar heelwat onsekerheid by die jong vakbonde hieromtrent bestaan.

\section{SLOT}

Dit is verblydend dat al die deelnemende partye oor die grondbeginsels van kollektiewe bedinging saamstem. Dit is egter oor die wyse van implementering of funksionering dat daar heelwat verdeeldheid tussen die onderskeie partye bestaan. Die verdeeldheid wat voorkom, kan aan tradisionele houdings toegeskryf word. Die ontwikkeling van rasse- en nywerheidsverhoudinge in Suid-Afrika en die ontstaan van houdings tydens die ontwikkelingsfases wat in vandag se situasie oorgedra word, is grootliks verantwoordelik vir die gebrek aan konsensus omtrent hoe kollektiewe bedinging moet geskied. Terwyl die verdeeldheid onder vakbonde in 'n groot mate aan die historiese ontwikkeling van nywerheidsverhoudinge toegeskryf kan word, wil dit voorkom of werkgewers in 'n mate onseker of besluitloos is omtrent die pad wat gevolg moet word omdat hulle met teenstrydige eise van vakbonde gekonfronteer word.

Die skrywers is van mening dat kritiese kollektiewe bedingingsaangeleenthede waaraan vir toekomstige ontwikkelinge aandag gegee moet word, die volgende insluit:

- $\quad$ sensitiwiteit by alle betrokke partye vir veranderende omstandighede om sodoende wetgewing, kollektiewe bedingingstrukture en houdings by hierdie buigsame omstandighede aan te pas.

- $\quad$ konsolidasie van veral vakbonde om fragmentasie van werknemer-verteenwoordiging te verminder. Verder kan daar moontlik gedink word aan 'n enkele sentrale liggaam waarby alle vakbonde in Suid-Afrika kan affilieer.

- $\quad$ verkryging van duidelikheid omtrent gesentraliseerde en gedesentraliseerde bedinging. Daar kan moontlik aan die tipiese Wes-Duitse stelsel gedink word wat plaaslike-, 
streeks- en nasionale bedinging akkommodeer. Dit is dus noodsaaklik dat die status van die onderskeie bedingingsmasjinerie uitgeklaar word.

- $\quad$ stroombelyning van die rol en funksionering van die Nywerheidshof om die geloofwaardigheid daarvan te verhoog.

- $\quad$ bewustheid deur veiligheidsowerhede van die implikasies van hulle optrede op die bedryf asook 'n meer duidelike en aanvaarbare beleid ten opsigte van hulle hantering van arbeidsleiers

- besliste wil van bedingingspartye om wel konstruktief en met integriteit te beding tot voordeel van elke indiwidu en organisasie se ekonomiese en maatskaplike welvaart.

Die proses van ontwikkeling ten opsigte van bogenoemde aangeleentheid kan deur onder andere opleiding vergemaklik word. Heelwat onkunde en verwarring bestaan tans onder die partye tot nywerheidsverhoudinge in Suid-Afrika omtrent die werklike bedingingsituasie. Hierdie toestand, wat tot verhoogde arbeidskonflik lei, kan deur doelgerigte opleiding wat oor 'n breë front geskied geminimaliseer word. Verbeterde opleiding in nywerheidsverhoudinge behoort die aflegging van tradisionele en konflikterende houdings en die aanvaarding van die verantwoordelikheid vir arbeidsvrede deur alle betrokke partye te verhaas.

Politieke en ekonomiese stabiliteit in Suid-Afrika kan slegs voortduur indien arbeidsvrede deur die prosesse van nywerheidsverhoudinge en kollektiewe bedinging gewaarborg kan word. Daarom moet hierdie prosesse met sensitiwiteit en verantwoordelikheid tot bevrediging van alle betrokke partye, gehanteer word.

\section{OPSOMMING}

Die gebrek aan konsensus aangaande ' $n$ ideale nywerheidsverhoudinge- en kollektiewe bedingingsisteem vir Suid-Afrika kan toegeskryf word aan die verskillende houdings van die onderskeie partye daarby betrokke. Dit lei op sy beurt weer tot konflik tussen die onderskeie partye. 'n Vergelykende literatuurstudie van die kollektiewe bedingingsisteem van vier lande (tewete V.S.A. Brittanje, Wes-Duitsland en Suid-Afrika) is gedoen ten einde konflikaangeleenthede in die Suid-Afrikaanse kollektiewe bedingingsisteem te identifiseer. 'n Ewekansige steekproef van 165 werkgewers en 75 vakbonde in die SuidAfrikaanse vervaardigingsbedryfstak is in die studie betrek. Die houdinge aangaande die geïdentifiseerde konflikaangeleenthede is met behulp van 'n Likertvraelys verkry. Die resultate dui op sterk meningsverskille tussen die deelnemende groepe omtrent die doeltreffendheid van die bestaande nywerheids- 
verhoudinge- en kollektiewe bedingingstelsel in Suid-Afrika.

Aanbevelings vir toekomstige navorsing en ontwikkelingswerk word gemaak.

\section{VERWYSINGS}

Barbash, J. American Unions: Structure, government and politics. New York: Random House, 1967.

Clegg, H.A. The changing system of industrial relations in Great Britain. Oxford: Basil Blackwell, 1979.

Holley, W.H. en Jennings, M. The labour relations process. Hiusdale, Illinois: Dryden, 1980.

Kamffer, H.O.L. ' $n$ Bedryfsielkundige studie van kollektiewe bedinging binne die SuidAfrikaanse vervaardigingsbedryfstak. Johannesburg: RAU. Magisterverhandeling, 1983.

Weber, A.A. Collective bargaining: Problems and Perspectives. Chicago: Free Press of Glencoe, 1961. 